\title{
Hot Water Extraction of Crude Polysaccharide from Codonopsis pilosula and Determination of the Rheological Properties
}

\author{
MINGJUN YANG ${ }^{1 *}$, NEHIKHARE EFEHI ${ }^{1}$, YONGMING JIN ${ }^{1}$, QINGCHUN ZHANG ${ }^{2}$, \\ ABDOL GHAFFAR EBADI ${ }^{3}$, MOHSEN TOUGHANI ${ }^{4}$ \\ ${ }^{1}$ School of Life Science and Engineering, Lanzhou University of Technology, Lanzhou 730050, China \\ ${ }^{2}$ Kangxian County Agricultural Technology Extension Center, Gansu Province, China \\ ${ }^{3}$ Department of Agriculture, Jouybar Branch, Islamic Azad University, Jouybar, Iran \\ ${ }^{4}$ Department of Fishery, Islamic Azad University Babol Branch, Babol, Iran
}

\begin{abstract}
The extraction condition of crude polysaccharides from Codonopsis pilosula by hot water reflux method was studied and the results analyzed by kinetic model. Then, the extraction rate and maximum extraction temperature were determined. furthermore, the thermal and $\mathrm{pH}$ stability and the rheological properties of the crude polysaccharide were also studied. crude Codonopsis pilosula polysaccharide (CCPP) under different conditions was extracted by hot water reflux method, the content was determined by phenol-sulfuric acid and DNS method, and the kinetic model of the extraction process was established. The viscosity was determined under different solute concentration, salt concentration, rotation speed, $\mathrm{pH}$, and temperature. The thermal stability and $\mathrm{pH}$ stability were determined; the protein content and sulfate ion content were determined by the coomassie brilliant blue method and barium sulfate turbidimetry method, respectively. The yield of CCPP by the hot water reflux method was $25.72 \%$. At $50{ }^{\circ} \mathrm{C}$, the maximum extraction concentration, the rate constant and the linear relationship between the rate constant and the time were obtained at different ratios of material to liquid. The extraction process of this experiment coincided with Fick's second law, R2 was greater than 0.88 and with the increase of extraction time, the dissolution rate increased, but with the increase of the ratio of material to liquid, the dissolution rate was decreased. CCPP showed a loss of polysaccharide fluidity as temperature increased and was affected by $\mathrm{pH}$ change. The apparent viscosity was affected by a change in solute concentration, temperature, $\mathrm{pH}$, rotation speed and salt and sucrose concentrations.
\end{abstract}

Keywords: Codonopsis pilosula, Polysaccharide Viscosity, Kinetic model, Stability; Physicochemical

\section{Introduction}

Codonopsis pilosula is a medicinal plant of the family Campanulaceae that is predominantly found in Asia [1]. There are about 40 Codonopsis species that can be found in China [2], and among them, Codonopsis pilosula is the most popular. It has long been used in Chinese medicine as a natural herb and also occasionally as a substitute of Panax ginseng [3]. The roots of Codonopsis pilosula have been reported to have also been used in traditional Chinese medicine for the treatment of asthma, cough, and psychoneurosis [4-5] and there are reports that Codonopsis species contain phytochemicals such as polysaccharides, triterpenoids, alkaloids, flavones, polyacetylenes, etc some of which are responsible for its bioactivities [1,3].

Literature report of the study of bioactive polysaccharides isolated from medicinal plants is becoming large and increasing because of their industrial and pharmacological potentials. Currently, about thirty polysaccharides have been studied in clinical trials [6] and many methods have been developed and applied to extract and purify bioactive polysaccharides from natural sources. Some of the commonly used extraction methods include hot water extraction, acid or alkali extraction, ultrasound-assisted extraction, enzyme hydrolysis, and microwave assisted extraction [7]. In recent

\footnotetext{
*email:yangmj@lut.cn; mingjun.yang.51@inbox.ru
} 
times, there is an increasing interest in the extraction and purification of secondary metabolites and phytochemicals including bioactive polysaccharides from codonopsis pilosula because of the importance of the plant in traditional Chinese medicine and many scholars have reported their studies of extraction of polysaccharides from codonopsis pilosula. But the use of different extraction and purification methods often influence the modification and bioactivities of the polysaccharides [6,8], hence the yields and physicochemical properties often reported are different. In this study, polysaccharide extraction technology was studied and the maximum extraction yield was obtained using hot water reflux method. Also, the kinetics model for the reaction was established and the thermal and $p \mathrm{H}$ stability and rheological properties of the polysaccharide were evaluated. It is hoped that the result will contribute to the current knowledge of extraction of polysaccharides from $C$. pilosula and help to further expand its use in food and medicine.

\section{Materials and methods}

\subsection{Preparation of sample and extraction of polysaccharides}

Dried roots of Codonopsis pilosula were purchased from Longnan city, Gansu province, China. The root was crushed into fine powered in a blender (Tianjin Taisite Instrument Co. Ltd., Tianjin, China) and sifted through a sieve of 60 mesh sizes. About $5.0 \mathrm{~g}$ each of the fine powder was transferred into a tripod bottle and labeled, distilled water was added according to four different solid to liquid $(\mathrm{g} / \mathrm{mL})$ ratios $(1: 15,1: 20,1: 25$, and 1:30) and heated in a water bath with occasional stirring for hot water extraction (extraction time: $0.5,1,1.5$, and $2.5 \mathrm{~h}$; extraction temperature: 50 , 60,70 , and $\left.80{ }^{\circ} \mathrm{C}\right)$. The mixture was centrifuged $(4000 \mathrm{r} / \mathrm{min}$ for $15 \mathrm{~min})$, filtered and the supernatant collected. $95 \%$ ethanol of 4 times its volume was added to it for ethanol precipitation and then placed in the refrigerator $\left(4^{\circ} \mathrm{C}\right)$. After 12 hours, it was centrifuged $(4500 \mathrm{r} / \mathrm{min}$ for $20 \mathrm{~min})$ and the precipitate was collected and dried to obtain $C$. pilosula crude polysaccharides termed CCPP. The determination of the total polysaccharide content was done using the phenol-sulfuric acid method and the polysaccharide yield (\%) was calculated according to the equation:

$$
\text { Polysaccharide yeild }(\%)=\frac{W 1}{W 2} \times 100
$$

where, $\mathrm{W}_{1}$ is weight of the polysaccharide and $\mathrm{W}_{2}$ is weight of the raw material in gram, respectively. All chemicals used in this study were analytical grade.

\subsection{Establishment of the Kinetic model}

The kinetic analysis of the extraction process was established based on Fick's second law. For the purpose of this study, the grounded solid particles of Codonopsis pilosula were regarded as spherical, and the following assumptions were made:

i.The pulverized fruiting bodies were uniform spherical particles, and the shape of the particles remained almost unchanged throughout the extraction process.

ii.At the beginning of extraction and at any sampling interval, the components in the particles were uniformly distributed and the quality of polysaccharide components was maintained. The concentration and diffusion coefficient of polysaccharides remain unchanged.

iii.The diffusion of polysaccharides is carried out radially from the inside of the particle.

iv.The mass transfer resistance on the surface of the particles is neglected; assuming that the solid particles of $C$. pilosula are spherical, the radius is $\mathrm{R}$, the volume of the solvent in the particle is $\mathrm{V}_{\mathrm{i}}$, and the effective component at time $\mathrm{t}$ is $\mathrm{r}$ from the surface of the sphere. The mass concentration of polysaccharide is $\mathrm{c}$, the mass concentration of the main active component in the liquid phase is $\mathrm{C}_{\text {out }}$, the average concentration of polysaccharide in the particle is $\mathrm{C}_{\mathrm{I}}$, and the internal diffusion coefficient is $\mathrm{D}_{\mathrm{S}}$. According to Fick's second law of diffusion:

$$
\frac{\partial c}{\partial t}=D_{S}\left(\frac{\partial^{2} c}{\partial r^{2}}+\frac{2}{r} \frac{\partial c}{\partial r}\right)
$$




$$
f=c \cdot r, \frac{\partial f}{\partial t}=D_{S} \frac{\partial^{2} f}{\partial r^{2}}
$$

The boundary conditions are: $\mathrm{r}=0, \mathrm{f}=0$

$$
r=R,\left(\frac{\partial C_{\text {out }}}{\partial t}\right) \cdot V_{\text {out }}=-D_{S} S\left(\frac{\partial c}{\partial r}\right)_{r=R}
$$

In the formula, the contact area between the particle and the solvent is obtained, according to the Fourier transformation method.

$$
\left(C_{\infty}-C\right) /\left(C_{\infty}-C_{0}\right)=\left(6 / \pi^{2}\right) \sum_{\pi=1}^{\infty}\left\{\exp \left[-(n \pi / R)^{2} D_{S} t\right]\right\}
$$

Because the distribution of concentration is infinite series, its high order term tends to zero and can be neglected.

$$
\left(C_{\infty}-C\right) /\left(C_{\infty}-C_{0}\right)=\left(6 / \pi^{2}\right)\left[\exp \left(-\pi^{2} D_{S} t / R\right)\right]
$$

The logarithm of pairs (6) is obtained:

$$
\ln \left[C_{\infty} /\left(C_{\infty}-C_{0}\right)\right]=k t+\ln \left[\pi^{2} C_{\infty} / 6\left(C_{\infty}-C_{0}\right)\right] \quad k=\pi^{2} D_{S} / R^{2}
$$

Note: Equations (6) and (7) are the obtained kinetic equations, which reflect the relationship between the radius of particles, temperature, extraction time and the concentration of polysaccharide.

\subsection{Determination of physicochemical properties of CCPP}

\subsubsection{Determination of total carbohydrate, protein and sulfate content}

The phenol-sulfuric acid method with glucose as standard was used to determine the carbohydrate content [9]. The protein content was determined by Bradford method using bovine serum albumin as the standard [10], while barium sulfate turbidimetry was used to estimate the sulfate content [11].

2.3.2. Thermal and $\mathrm{pH}$ stability

To test the thermal stability of CCPP, $0.05 \mathrm{~g}$ of CCPP sample was dissolved in $50 \mathrm{ml}$ water to make $1 \mathrm{mg} / \mathrm{mL}$ solution. The CCPPs solution was then allowed to heat for $2 \mathrm{~h}$ in a water bath (heating temperatures: $40,50,60,70,80,90$, and $100^{\circ} \mathrm{C}$ ) and the absorbance value was measured at $490 \mathrm{~nm}$ by the phenol-sulfuric acid method. Fresh samples were used in all physicochemical and rheological measurements, each test was done in triplicate and the average values were obtained. For the $\mathrm{pH}$ stability test, CCPP (0.05 g) was dissolved in $50 \mathrm{~mL}$ water. The $\mathrm{pH}$ of the CCPPs solution was adjusted with acid and alkali and the absorbance $\left(\mathrm{OD}_{490} \mathrm{~nm}\right)$ value was measured at $\mathrm{pH}$ 1-13.

\subsection{Measurement of rheological properties of CCPP}

\subsubsection{Effect of the rotation speed on viscosity of CCPP}

$3 \mathrm{mg} / \mathrm{mL}$ of CCPP solution (CCPPs) was prepared. The solution was stirred for proper mixing and then allowed to settle at room temperature. The apparent viscosity of CCPPs was measured at different rotational speeds $(0.3,0.6,1.5,3,6,12,30$, and $60 \mathrm{r} / \mathrm{min})$.

\subsubsection{Effect of concentrations on viscosity of CCPP}

Solutions of CCPP $(0.8,1,2,3,4$, and $5 \mathrm{mg} / \mathrm{mL})$ were separately prepared, stirred and allowed to settle at room temperature. Then the apparent viscosity was measured at $1.5 \mathrm{r} / \mathrm{min}$ rotational speed.

\subsubsection{Effect of temperature on viscosity of CCPP}

CCPP solution of a fixed concentration $(3 \mathrm{mg} / \mathrm{mL})$ was heated to the following temperatures 20,30 , $40,50,60,70$, and $80 \mathrm{oC}$ in a hot water bath. The apparent viscosity at each test temperature was measured at $1.5 \mathrm{r} / \mathrm{min}$. 


\subsubsection{Effect of $p H$ change on viscosity of CCPP}

The viscosity of $3 \mathrm{mg} / \mathrm{mL}$ CCPP solution was measured at $\mathrm{pH} \mathrm{1,3,5,7,9,11,} \mathrm{and} 13$. The rotational speed was fixed at $1.5 \mathrm{r} / \mathrm{min}$.

\subsubsection{Effect of salts and sucrose concentrations}

$0.5,1.0$, and $1.5 \mathrm{mg} / \mathrm{mL}$ of salt $\left(\mathrm{NaCl}, \mathrm{KCl}, \mathrm{ZnCl} 2\right.$, and $\left.\mathrm{CaCl}_{2}\right)$ and sucrose solutions were prepared, and added to $3 \mathrm{mg} / \mathrm{mL}$ of CCPP solution separately. The mixture was then shaken for proper dissolution of the polysaccharide molecules and then allowed to settle at room temperature. The apparent viscosity of the new solution was determined at $1.5 \mathrm{r} / \mathrm{min}$ rotational speed.

\section{Results and discussions}

\subsection{Polysaccharide yield and kinetic model}

In this experiment, $129 \mathrm{~g}$ C. pilosula was used and $33.18 \mathrm{~g}$ crude polysaccharide was obtained by hot water extraction and ethanol precipitation. Therefore, the yield of crude polysaccharide extracted from $C$. pilosula by hot water reflux method was calculated to be $25.72 \%$. The dynamic parameters (The regression equations and observed rate constants) of the kinetic study for the extraction process were summarized in Table 1.

Table 1. Dynamic parameters at different material to liquid ratios

\begin{tabular}{ccccc}
\hline Material to liquid ratio & $\mathrm{C} \infty$ & $\ln [\mathrm{C} \infty /(\mathrm{C} \infty-\mathrm{C})]$ & Fitted linear equation & $\mathrm{R}^{2}$ \\
\hline $1:$ & 469.86 & 0.73 & $\mathrm{y}=3.7791 \mathrm{x}-1.8085$ & 0.9251 \\
$1: 20$ & 421.91 & 0.57 & $\mathrm{y}=2.4577 \mathrm{x}-0.9585$ & 0.8889 \\
$1: 25$ & 329.86 & 0.98 & $\mathrm{y}=0.55 \mathrm{x}+0.6805$ & 0.9942 \\
$1: 30$ & 196.74 & 1.17 & $\mathrm{y}=0.5907 \mathrm{x}+0.857$ & 0.9951 \\
\hline
\end{tabular}

The maximum extraction concentration, the rate constant and the linear relationship between the rate constant and time were obtained at $50{ }^{\circ} \mathrm{C}$ at different ratio of material to liquid. From Table $1, \mathrm{R}^{2}$ was greater than 0.88 at the different material to liquid ratios and fixed temperature, showing that the extraction process coincides with the Fick's second law. In addition, Figure 1 was a linear relationship graph fitted according to Fick's second law at 50,60,70, and $80^{\circ} \mathrm{C}$, respectively. The results showed that the dissolution rate of crude polysaccharides from $C$. pilosula increased with the increase of extraction time, but decreased with the increase of material-liquid ratio.
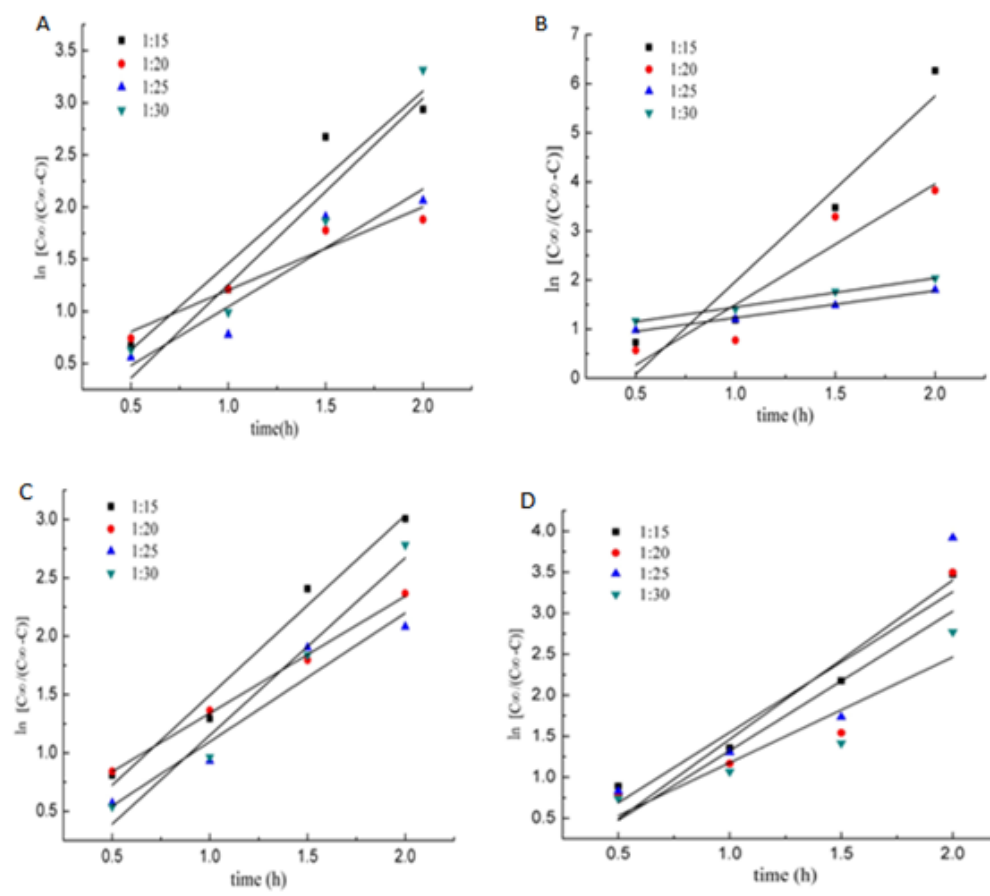

Rev. Chim., 71 (5), 2020, 441-449

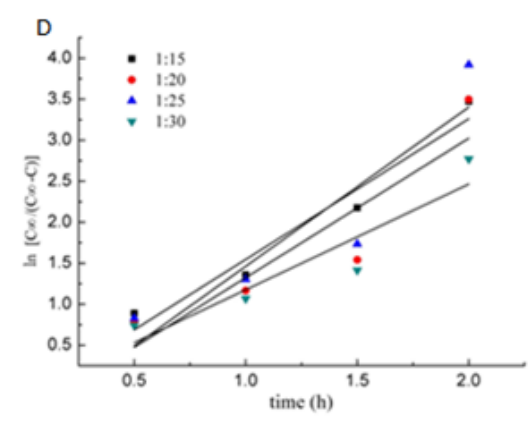

Figure 1. Linear relationship between $\ln \left(C_{\infty} / C_{\infty}-C\right)$ and $t$ at (A) $50^{\circ} \mathrm{C}$, (B) $60^{\circ} \mathrm{C}$, (C) $70^{\circ} \mathrm{C}$, and (D) $80^{\circ} \mathrm{C}$ 


\subsection{Physicochemical properties of CCPP}

Table 2 showed the standard curve linear regression and the calculated content of protein and sulfate in CCPP. Protein content was $0.36 \%$ by Bradford method, and sulfate content was $13.89 \%$ by turbidimetry method.

Table 2. Content of protein and sulfate in polysaccharide

\begin{tabular}{|c|c|c|c|}
\hline Items & Standard curve & $\mathrm{R}^{2}$ Value & Content \\
\hline $\begin{array}{l}\text { Protein content of } \\
\text { polysaccharide }\end{array}$ & $y=1.712 x+1.3942$ & 0.9816 & $0.36 \%$ \\
\hline $\begin{array}{l}\text { Sulfate content of } \\
\text { polysaccharide }\end{array}$ & $y=3.893 x+0.3672$ & 0.9909 & $13.89 \%$ \\
\hline
\end{tabular}

Results of the thermal and pH stability of CCPP were displayed in Figure 2(A) and(B). The heat treatment under the condition of normal pressure brought about an accompanying loss of polysaccharide fluidity (gelation) as the temperature increases towards $100{ }^{\circ} \mathrm{C}$. This phenomenon may have resulted from the physical association of its polymer chains through hydrogen bonding and development of hydrophobic interactions [12-15]. Gelation was more significant from 60 to $80{ }^{\circ} \mathrm{C}$ and the gelation temperature was taken to be $60{ }^{\circ} \mathrm{C}$. From Figure 2(B), the polysaccharide was unstable when subjected to $\mathrm{pH}$ treatment, its stability significantly decreasing as $\mathrm{pH}$ value tends to alkaline.
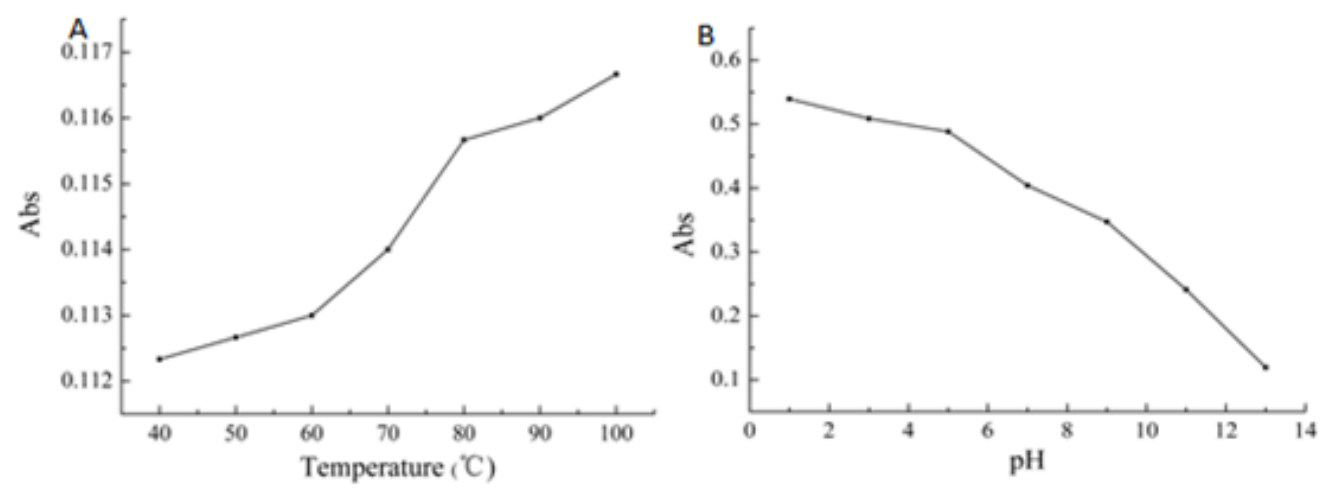

Figure. 2. Thermal and $p \mathrm{H}$ stability of CCPP

\subsection{Rheological properties of CCPP}

\subsubsection{Effect of rotation speed and concentration on apparent viscosity of CCPP}

Figure 3(A) showed the effect of changing rotation speed on the apparent viscosity of CCPP.

The apparent viscosity decreased with increasing rotation speed (shear-thinning) at the same concentration $(3 \mathrm{mg} / \mathrm{mL})$ and temperature $\left(25^{\circ} \mathrm{C}\right)$, a behaviour that was characteristic of Pseudoplastic fluids [16].
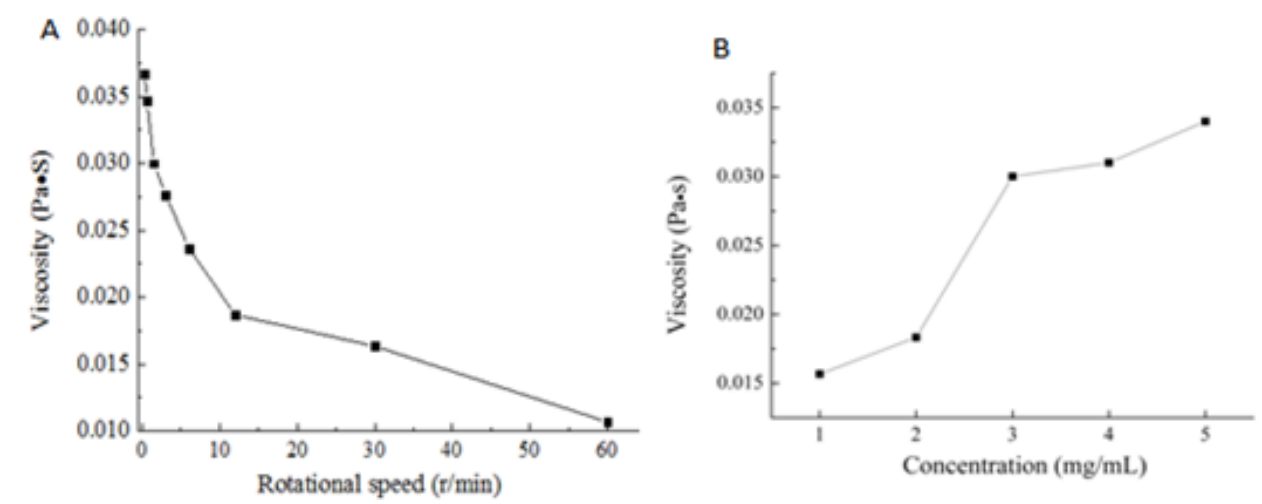

Figure 3. Effect of Rotational speed and solute concentrations on apparent viscosity of CCPP solution 
The effect of solute concentration on the viscosity of CCPP was measured at $1.5 \mathrm{r} / \mathrm{min}$ rotation speed and the temperature was fixed at $25^{\circ} \mathrm{C}$. As shown in Figure 3(B), the apparent viscosity of CCPP increased as the solute concentration increased. Wang et al. [17] had earlier reported that solubility and viscosity of polysaccharide solutions were usually influenced by solute concentration. This could be due to the fact that the higher the solute concentration of the solution, the greater the degree of molecular interactions in the solution. Thus, the increased polysaccharide concentration led to enhanced interaction between the polysaccharide chains [18] eventually contributing to a greater viscosity of the polysaccharide solution.

\subsubsection{Effect of temperature and $\mathrm{pH}$ on apparent viscosity of CCPP}

Figure 4(A) showed how a change in temperature affected the viscosity of CCPP. From the data in this study, it can be seen that at a concentration of $3 \mathrm{mg} / \mathrm{mL}$ and $1.5 \mathrm{r} / \mathrm{min}$ rotation speed, the apparent viscosity of CCPP decreased steadily as the temperature increased from 20 to $80{ }^{\circ} \mathrm{C}$. This could be due to the increase of molecular energy that is required for molecular mobility so that the distance between the molecules became widen with less internal friction (reduction of their cohesiveness) [19] resulting in the decrease in the apparent viscosity of the polysaccharide solution [19-21]. Another reason could be that the increase in temperature resulted in the decomposition of the polysaccharide, causing a change in its structure and thus, reducing the viscosity of the solution. According to Fig. 4(B), changing the $\mathrm{pH}$ from the neutral $p \mathrm{H}$ of 7.0 caused a corresponding change in the conformation of the polysaccharide molecules which was in agreement with a previous report by Medina-Torres et al.[22]. Thus, resulting in the change (decrease) of the viscosity of the solution. Obviously, the lowest viscosity of the solution was recorded at $p \mathrm{H} 1.0$ and 13 indicating its instability under strong acidic and alkaline conditions.
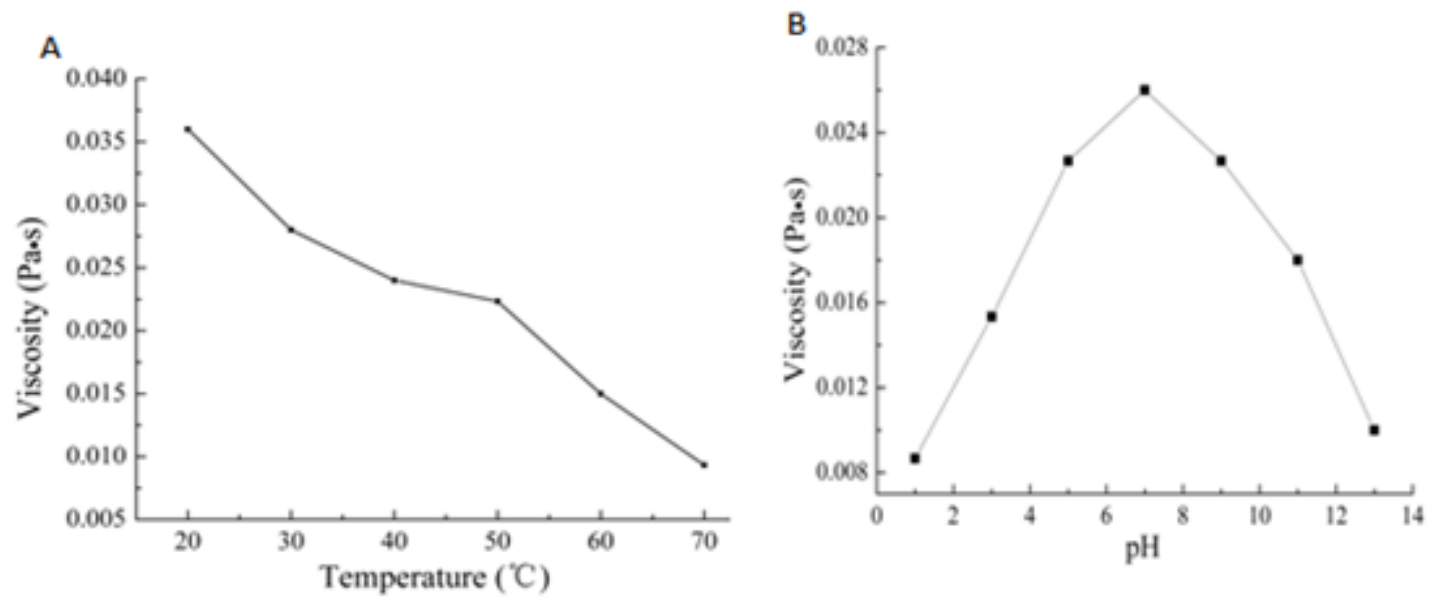

Figure 4. Effect of temperature and $p \mathrm{H}$ on apparent viscosity of CCPP solutions

\subsubsection{Effect of different salt concentrations and Sucrose solution on apparent viscosity of CCPP}

The presences of metal ions in a polysaccharide solution often lead to a change in the electric charge distribution of the polysaccharide molecules, thus affecting the viscosity of the polysaccharide solution [17]. In Fig. 5, the effects of sodium chloride, potassium chloride, zinc chloride, calcium chloride and sucrose on the viscosity of CCPP solutions were given. In all, the presence of the metal ions affected the viscosity of CCPPs. An increase in salt concentration led to a corresponding increase in viscosity of CCPP. By comparing the apparent viscosities of CCPP in the presence of $\mathrm{NaCl}, \mathrm{KCl}, \mathrm{ZnCl}_{2}$, and $\mathrm{CaCl}_{2}$ at the same ionic strength, it was observed that the effects of the divalent salts $\left(\mathrm{CaCl}_{2}\right.$ and $\left.\mathrm{ZnCl}_{2}\right)$ were stronger on the viscosity of CCPP than that of the monovalent salts $(\mathrm{NaCl}, \mathrm{KCl}$,).

These findings agreed with the previous report of Wang et al that in the salt of higher concentration, the effect of $\mathrm{Ca}^{2+}$ on polysaccharide viscosity was stronger than that of $\mathrm{K}^{+}$. This was 
attributed to the fact that polysaccharides containing a high amount of uronic acid (acidic polysaccharides with carboxyl groups) were able to undergo complex reaction in the presence of divalent cations to form a salt bridge, thus improving its apparent viscosity. Furthermore, comparing the effects of all the salt solutions on CCPP viscosity, the effect of $\mathrm{ZnCl}_{2}$ was strongest [17-25].

Also, as can be seen from Fig. 5, the viscosity of CCPP increased significantly as the sucrose concentration increased. First of all, it was worth noting that the presence of sucrose might contribute itself to the viscosity of the solution. Also was the fact that the hydration of its molecule in the solution will reduce the amount of free water, strengthening the interaction of the CCPP molecular chain and enhancing polymerization of hydrogen bonds between the polysaccharides, thus leading to the increased viscosity of the polysaccharide solution [26-35].

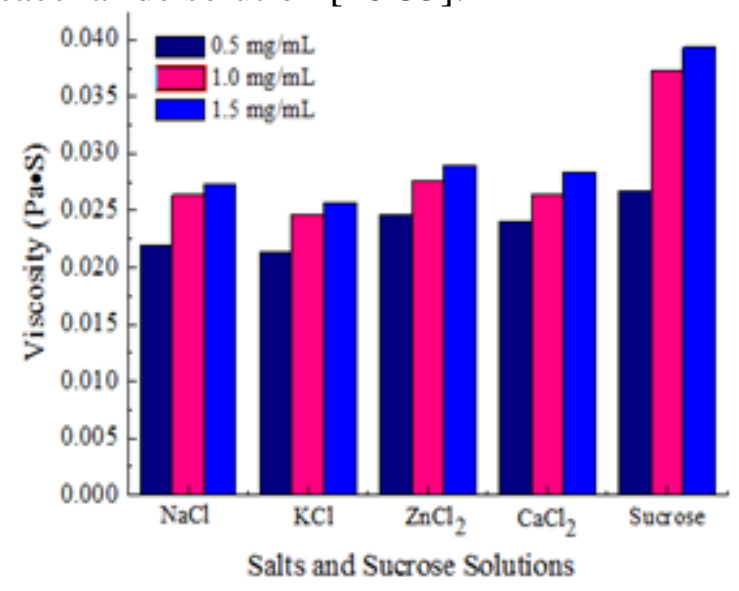

Figure 5. Effect of salt $\left(\mathrm{NaCl}, \mathrm{KCl}, \mathrm{ZnCl}_{2}\right.$, and $\left.\mathrm{CaCl}_{2}\right)$ and Sucrose concentrations on apparent viscosity of CCPP

\section{Conclusions}

Hot water reflux method was used for the polysaccharide extraction and the polysaccharide yield of $25.72 \%$ was obtained. The extraction process was consistent with Fick's second law and $\mathrm{R}^{2}>0.88$. CCPP apparent viscosity was affected by temperature, rotational speed, solute concentration, $\mathrm{pH}$ and presence of metal ions. The apparent viscosity increased with increased in solute concentration but decreased with increasing temperature and rotation speed (Pseudoplastic fluid). At the same concentration, divalent cations had a stronger effect on the viscosity of CCPP than monovalent cations suggesting that CCPP could be acidic polysaccharides with carboxyl groups. Increase in sucrose concentration also significantly increased the viscosity of CCPP. The results from this study support the potential usefulness of CCPP in food and drug applications although further analysis will be needed to fully describe its other physicochemical and rheological properties and also its full biochemical composition.

Acknowledgements. This study was financially supported by the National Natural Science Foundation of China (No. 81660581).

\section{References}

1.HE, J.Y., MA, N., ZHU, S., KOMATSU, K., LI, Z.Y., FU, W.M., The genus Codonopsis (Campanulaceae): a review of phytochemistry, bioactivity and quality control, J. Nat. Med., 69, $2015,1-21$.

2.GAO, S., WANG, H., ZENG, C., HOU, J., ZHANG, Y., Phytochemical and pharmacological properties of Radix Codonopsis : a review, J. Med. Res. Dev., 1, 2012, 16-22.

3.LI, C.Y., XU, H.X., HAN, Q.B., WU, T.S., Quality assessment of Radix Codonopsis by 
quantitative nuclear magnetic resonance, J. Chromatogr. A., 1216(11), 2009, 2124-2129.

4.ICHIKAWA, M., OHTA, S., KOMOTO, N., USHIJIMA, M., KODERA, Y., HAYAMA, M., SHIROTA, O., SEKITA, S., KUROYANAGI, M., Simultaneous determination of seven saponins in the roots of Codonopsis lanceolata by liquid chromatography-mass spectrometry, $J$. Nat. Med., 63, 2009, 52-57.

5.WANG, Z.T., MA, G.Y., TU, P.F., XU, G.J., NG, T.B., Chemotaxonomic study of Codonopsis (family Campanulaceae) and its related genera, Biochem. Syst. Ecol., 23, 1995, 809-812.

6.CHEN, Y., YAO, F., MING, K., WANG, D., HU, Y., LIU, J., Polysaccharides from traditional Chinese medicines: extraction, purification, modification, and biological activity, Molecules., 21(12), 2016, 1705-1727.

7.ARASI, M.A.S.A.G., RAO, M.G., BAGYALAKSHIMI, J., The comparison and analysis of two extraction methods for polysaccharides in Psidium guajava L. fruits, Indian. J. Pharm. Educ. Res., 50, 2016, 218-224.

8.SHI, L., Bioactivities, isolation and purification methods of polysaccharides from natural products: A review, Int. J. Biol. Macromol., 92, 2016, 37-48.

9.KLAUS, A., KOZARSKI, M., NIKSIC, M., JAKOVLJEVIC, D., TODOROVIC, N., LJLD, V.G., Antioxidative activities and chemical characterization of polysaccharides extracted from the basidiomycete Schizophyllum commune, Food. Sci. Technol., 44, 2011, 2005-2011.

10.ZHANG, X., YU, L., BI, H., LI, X., NI, W., HAN, H., LI, N., WANG, B., ZHOU, Y., TAI, G., Total fractionation and characterization of the water-soluble polysaccharides isolated from Panax ginseng C. A. Meyer, Carbohydr. Polym., 77, 2009, 544-552.

11.BHADJA, P., TAN, C. Y., OUYANG, J. M., YU, K., Repair effect of seaweed polysaccharides with different contents of sulfate group and molecular weights on damaged HK-2 cells, Polymers., 8(5), 2016, 188.

12.HOLME, K.R., HALL, L.D., Chitosan derivatives bearing C10-alkyl glycoside branches: a temperature-induced gelling polysaccharide, Macromolecules., 24, 1991, 3828-3833.

13.WILLIAMS, P.A., PHILLIPS, G.O., Introduction to food hydrocolloids, Hand. hydrocoll., 2009, 122.

14.RINAUDO, M., Gelation of Polysaccharides, J. Intell. Mater. Syst. Struct., 4, 1993, 210-215.

15.SAHA, D., BHATTACHARYA, S., Hydrocolloids as thickening and gelling agents in food: a critical review, J. Food. Sci. Tech., 47(6), 2010, 587-597.

16.CHEN, G., CHEN, K., ZHANG, R., CHEN, X., HU, P., KAN, J., Polysaccharides from bamboo shoots processing by-products: New insight into extraction and characterization. Food. Chem., 245, 2018, 1113-1123.

17.WANG, X., WANG, X., HE, S., SUN, H., WANG, P., ZHANG, P., LOU, Q., XIE, Y., ZHANG, M., CONTRIBUTED, S.H., The rheological properties of polysaccharides from rapeseed, Curr. Top. Nutraceutical. Res., 13, 2015, 197-204.

18.ZHANG, T. H., ZHANG, C. H., LIU, D. R., ZHANG, X., DA, L. I., YANG, Z. N., Rheological properties of the exopolysaccharide produced by Streptococcus thermophilus ST1, Food. Sci., 32, 2011, 62-65.

19.WU, Y., DING, W., JIA, L., HE, Q., The rheological properties of tara gum (Caesalpinia spinosa), Food. Chem., 168, 2015, 366-371.

20.ABBASTABAR, B., AZIZI, M.H., ADNANI, A., ABBASI, S., Determining and modelling rheological characteristics of Quince seed gum, Food. Hydrocoll., 43, 2015, 259-264.

21.MILANI, J., GHANBARZADEH, B., MALEKI, G., Rheological Properties of Anghouzeh Gum, Int. J. Food. Eng., 8(3), 2012, 14-23.

22.MEDINA-TORRES, L., BRITO-DE LA FUENTE, E., TORRESTIANA-SANCHEZ, B., KATTHAIN, R., Rheological properties of the mucilage gum (Opuntia ficus indica), Food. Hydrocoll., 14, 2000, 417-424. 
23.CAMERON, L., ABDELKREIM, M., Estimation of Productivity for Acacia seyal (Delile) in Alazzazah Area. Ccamlr Sci., 25(4), 2018, 287-291.

24.COOPER, R., NEWMAN, P., HERACHWATI, N., RAPD Molecular Markers to Analyze the DNA Variation of the Three Bruguiera Species on Kemujan Island. Ccamlr Sci., 25(3), 2018, 209-214.

25.KING, J., SMITH, S., Arachidonic Acid Content in the Feed on the Growth Performance, Antioxidant Capacity and Fatty Acid Generation of Sea Cucumber. Ccamlr Sci., 25(2), 2018, 121-132.

26.HUANG, X. D., ZHANG, Q. Y., MA, X. L., The Thermal Comfort Models of Venue in Hot and Humid Subtropical Regions. Ccamlr Sci., 25(3), 2018, 244-252.

27.WANG, J. G., WANG, Z., WANG, Q., ZHOU, Z. Q., Spatio-Temporal Variation Characteristics of Ecological Environment Quality of Freshwater Crayfish Culture Waters in Australia. Ccamlr Sci., 25(3), 2018, 163-171.

28.ZHAO, M. J., Combined Ecological Floating Bed on Soluble Inorganic Nitrogen in Overlying Water. Ccamlr Sci., 25(3), 2018, 202-208.

29.ZHENG, Y., ZHANG, H. M., The Method of Color Element Allocation of Ornamental Plants Considering Water Condition. Ccamlr Sci., 25(3), 2018, 261-271.

30.ASHRAF, M. A., LIU, Z. L., PENG, W. X., GAO, C. X., New Copper Complex on Fe3O4 Nanoparticles as a Highly Efficient Reusable Nanocatalyst for Synthesis of Polyhydroquinolines in Water. Catal. Lett., 150(3), 2020, 683-701.

31.YANG, F., YANG, F., WANG, G. Y., KONG, T., WANG, H., ZHANG, C. S., Effects of water temperature on tissue depletion of florfenicol and its metabolite florfenicol amine in crucian carp (Carassius auratus gibelio) following multiple oral doses. Aquaculture, 515, 2020, 9.

32.WANG, M., ZHANG, D. Q., CHENG, Y. N., TAN, S. K. (2019). Assessing performance of porous pavements and bioretention cells for stormwater management in response to probable climatic changes. J. Environ. Manage., 243, 2019, 157-167. doi:10.1016/j.jenvman.2019.05.012

33.WANG, H., AN, X. Q., ZHANG, Z. Y., Effect of advanced treatment on ammonia nitrogen contained in secondary effluent from wastewater treatment plant. Fresenius Environ. Bull., 27(4), 2018, 2043-2050.

34.KHATUA, S., ACHARYA, K., Alkali treated antioxidative crude polysaccharide from Russula alatoreticula potentiates murine macrophages by tunning TLR/NF-кB pathway. Sci. Rep., 9(1), 2019, $1-11$.

35.TANG, P. L., HAO, E., DU, Z., DENG, J., HOU, X., QIN, J., Polysaccharide extraction from sugarcane leaves: combined effects of different cellulolytic pretreatment and extraction methods. Cellulose, 26(18), 2019, 9423-9438.

$\overline{\text { Manuscript received: } 22.03 .2020}$ 